\title{
Oxyconformity in the intertidal worm Sipunculus nudus: the mitochondrial background and energetic consequences
}

\author{
Tanja Buchner, Doris Abele, Hans-O. Pörtner* \\ Alfred-Wegener-Institut for Polar and Marine Research, Department of Ecophysiology and Ecotoxicology, Columbusstrasse, \\ 27568 Bremerhaven, Germany
}

Received 4 April 2000; received in revised form 21 January 2001; accepted 29 January 2001

\begin{abstract}
The energetic consequences of strict oxyconformity in the intertidal worm $S$. nudus were studied by characterizing the $\mathrm{PO}_{2}$ dependence of respiration in mitochondria isolated from the body wall tissue. Mitochondrial respiration rose in a $\mathrm{Po}_{2}$ range between 2.8 and $31.3 \mathrm{kPa}$ from a mean of 56.5 to $223.9 \mathrm{nmol} \mathrm{O} \mathrm{mg}$ protein ${ }^{-1} \mathrm{~h}^{-1}$. Respiration was sensitive to both salicylhydroxamic acid (SHAM) and KCN. $P_{\mathrm{O}_{2}}$ dependence remained unchanged with saturating and nonsaturating substrate levels (malate, glutamate and ADP). A concomitant decrease of the ATP/O ratio revealed a lower ATP yield of aerobic metabolism at elevated $\mathrm{PO}_{2}$. Obviously, oxyconforming respiration implies progressive uncoupling of mitochondria. The decrease in ATP/O ratios at higher $\mathrm{Po}_{2}$ was completely reversible. Addition of $90.9 \mu \mathrm{mol} \mathrm{H}_{2} \mathrm{O}_{2}$ $1^{-1}$ did not inhibit ATP synthesis. Both observations suggest that oxidative injury did not contribute to oxyconformity. The contribution of the rates of mitochondrial ROS production and proton leakiness to mitochondrial oxygen consumption and uncoupling was investigated by using oligomycin as a specific inhibitor of the ATP synthase. The maximum contribution of oligomycin independent respiration to state 3 respiration remained below $6 \%$ and showed a minor, insignificant increase at elevated $\mathrm{Po}_{2}$, at a slope significantly lower than the increment of state 3 respiration. Therefore, $\mathrm{PO}_{2}$ dependent mitochondrial proton leakage or ROS production cannot explain oxyconformity. In conclusion $\mathrm{PO}_{2}$ dependent state 3 respiration likely relates to the progressive contribution of an alternative oxidase (cytochrome $o$ ), which is characterized by a low affinity to oxygen and an ATP/O ratio similar to the branched respiratory system of bacteria. The molecular nature of the alternative oxidase in lower invertebrates is still obscure. (c) 2001 Elsevier Science Inc. All rights reserved.
\end{abstract}

Keywords: Sipunculus nudus; Oxyconformity; Mitochondrial oxygen consumption; Mitochondrial ATP synthesis; Alternative electron pathway; Mitochondrial proton leakage; P/O ratio; Cytochrome $o$

\footnotetext{
Abbreviations: CCCP, carbonylcyanid-m-chlorophenylhydrazon; cyt- $o$, cytochrome $o$; DMSO, dimethylsulfoxide; $\mathrm{H}_{2} \mathrm{O}_{2}$, hydrogen peroxide; P/O, ATP/O ratio; $\mathrm{PO}_{2}$, oxygen partial pressure; RCR, respiratory control ratio; ROS, reactive oxygen species; SHAM, salicylhydroxamic acid

* Corresponding author. Tel.: +49-471/4831-1307; fax: +49-471/4831-1149.
} 


\section{Introduction}

Most intertidal invertebrates, especially the infauna, have to cope with highly fluctuating ambient oxygen conditions. In intertidal areas oxygen tensions in surface waters vary from almost 0 $\mathrm{kPa}$ at night to hyperoxic levels during daytime (Fenchel and Finlay, 1995). These high $\mathrm{Po}_{2}$ levels may cause increased oxygen concentrations in the burrows of intertidal species linked to an elevation of oxidative stress. The respiration rate of the intertidal worm Sipunculus nudus is strongly dependent on oxygen levels in the ambient water (Henze, 1910; Pörtner et al., 1985; Riefke, 1994). This $\mathrm{PO}_{2}$ dependent respiration is called oxyconform and has been found in many marine invertebrates (Mangum and van Winkle, 1973). In contrast, most if not all vertebrates maintain a constant rate of oxygen consumption under varying $\mathrm{Po}_{2}$, and are termed oxyregulators (Prosser, 1991; Pörtner and Grieshaber, 1993). In general, both oxyconformers and oxyregulators show a rapid decrease in oxygen uptake below a critical $\mathrm{PO}_{2}$ level $\left(P_{\mathrm{C}(\mathrm{I})}\right.$, Dejours, 1981) which marks the onset of anaerobic metabolism (Pörtner and Grieshaber, 1993). Many intermediate patterns between extreme oxyconformity and oxyregulation have been described (Mangum and van Winkle, 1973). In some cases aerobic oxyconformity only occurs in a low to medium range of $\mathrm{PO}_{2}$ above which respiration becomes saturated and oxyregulation prevails (Pörtner and Grieshaber, 1993; Fritzsche, 1995; Abele et al., 1998).

Isolated cells and mitochondria of oxyregulating animals also display $\mathrm{PO}_{2}$ independent respiration above $P_{\mathrm{C}(\mathrm{I})}$ (Jöbsis, 1974; Wilson et al., 1979; Jones and Kennedy, 1982; Wilson et al., 1988; Pörtner and Grieshaber, 1993). The reason for this is the high oxygen affinity of cyt $a / a_{3}$ (cytochrome $c$ oxidase, EC 1.11.1.7) in the inner mitochondrial membrane, which becomes saturated at low $\mathrm{Po}_{2}$ (Oshino et al., 1974; Jones and Kennedy, 1982). Accordingly, a constant maximal oxidation of cyt $c$ was measured above the critical $\mathrm{Po}_{2}$ with increasing $\mathrm{P}_{\mathrm{O}_{2}}$ (Oshino et al., 1974; Sugano et al., 1974; Jones et al., 1985). These relationships have not been investigated in oxyconforming animals. We hypothesized that a mitochondrial mechanism may form the basis of the strong oxyconformity of S. nudus. Pörtner and Grieshaber (1993) discussed the possibility of an alternative mitochon- drial electron pathway, known from bacteria, as an explanation for oxyconformity in marine invertebrates. This pathway is predicted to be characterized by a lower phosphorylation efficiency during $\mathrm{O}_{2}$ reduction, and will therefore yield lower $\mathrm{P} / \mathrm{O}$ ratios than the classical pathway.

The present paper aims at elucidating the mitochondrial background of oxyconformity in $S$. nudus. The first objective was to analyse whether mitochondria displayed $\mathrm{PO}_{2}$ dependent oxygen uptake and to investigate the energetic consequences. Are higher levels of oxygen consumption at elevated $\mathrm{PO}_{2}$ correlated to a higher ATP yield and turnover? The second aim was to investigate the possible contribution of proton leakiness or ROS (reactive oxygen species) formation to the expected progressive uncoupling of mitochondrial respiration at high ambient $P_{\mathrm{o}_{2}}$. The present data are discussed in the context of a companion study which compared $\mathrm{Po}_{2}$ dependent respiration in mitochondria of the bivalve Arctica islandica, the nereid worm Nereis pelagica and the bovine heart (Tschischka et al., 2000).

\section{Material and methods}

\subsection{Animals}

Specimens of Sipunculus nudus (4-9 g body weight) were collected in March and April from intertidal sandy beaches close to Morgat, in the vicinity of the Biological station of Roscoff, Brittany, France. After transport to the Alfred Wegener Institute in Bremerhaven, animals were kept in tanks with a $10-15 \mathrm{~cm}$ layer of sand from the original habitat and recirculated filtered natural full strength sea water at temperatures between 11 and $15^{\circ} \mathrm{C}$.

\subsection{Isolation of mitochondria}

Mitochondria were isolated at $0-3^{\circ} \mathrm{C}$ from body wall muscle tissue following a procedure modified after Riefke (1994). Muscle tissue (8-18 g) was rinsed with isolation buffer $\left(0.8\right.$ mol glycine $1^{-1}$, 0.172 mol sucrose $1^{-1}, 0.5$ mmol EGTA $1^{-1}, 10$ mmol HEPES $1^{-1}$ and $0.2 \%$ BSA), cut into small pieces and washed twice with isolation buffer. Tissue pieces were homogenized in a motor-driven glass-Teflon homogenizer (Heidolph, Kelheim, FRG) in isolation buffer $(\mathrm{w} / \mathrm{v} \approx 1: 20)$. The ho- 
mogenate was filtered through gauze and cellular debris was removed by centrifugation $(3500 \times g$, $10 \mathrm{~min})$. The resulting supernatant was filtered through gauze again. After repeated centrifugation (two times at $3500 \times \mathrm{g}, 10 \mathrm{~min}$ ) the combined supernatants were centrifuged at $16000 \times g$ for $30 \mathrm{~min}$. The final supernatant was discarded and the upper (mitochondrial) layer of the pellet was carefully resuspended in $150 \mathrm{ml}$ isolation buffer and centrifuged again $(16000 \times g, 30 \mathrm{~min})$. The mitochondrial pellet was resuspended in $2-4 \mathrm{ml}$ of respiration buffer $\left(0.55 \mathrm{~mol}\right.$ glycine $1^{-1}, 0.25$ mol sucrose $1^{-1}, 0.5$ mmol EGTA $1^{-1}, 10 \mathrm{mmol}$ HEPES $\mathrm{l}^{-1}, 5 \mathrm{mmol} \mathrm{MgCl}{ }_{2} \mathrm{l}^{-1}, 5 \mathrm{mmol} \mathrm{K}_{2} \mathrm{HPO}_{4}$ $1^{-1}$ and $0.2 \%$ BSA).

For the comparison of the methods, the content of mitochondrial protein was measured according to Bradford (1976) and Biuret (Kresze, 1983) using BSA (1-10 mg ml $\mathrm{m}^{-1}$ ) as a standard. Ultrasonic treatment or freezing of mitochondrial samples verified that protein extraction from mitochondria was complete. Mitochondrial protein concentrations when determined with the Bradford-assay resulted as $2303 \pm 0.523 \mathrm{mg} \mathrm{ml}^{-1}$ and as $5.02 \pm 1.17 \mathrm{mg} \mathrm{ml}^{-1}$ with the Biuret-method. Glycine interferes with the analysis according to Biuret (Rehm, 1996 and personal observations), therefore, protein concentrations determined according to Bradford were used throughout.

\subsection{Analyses}

\subsubsection{Chemicals}

Chemicals were obtained from FLUKA (Deisenhofen, FRG), unless stated otherwise and with the exception of hydrogen peroxide and $\mathrm{MgCl}_{2}$, which were purchased from Merck (Darmstadt, FRG), glycine, EGTA, HEPES, DMSO, BSA and ATP from SIGMA (Deisenhofen, FRG) and ADP from Boehringer (Mannheim, FRG). Mitochondrial substrates (glutamate, malate, ADP) as well as ATP and $\mathrm{P}^{1}, \mathrm{P}^{5}$-Di-(adenosin-5')-pentaphospate were dissolved in deionized water, at neutralized $\mathrm{pH}$ if necessary. Oligomycin and CCCP were dissolved in a solution containing 40\% DMSO. Added volumes of DMSO had no measurable effect on mitochondrial respiration.

\subsubsection{Mitochondrial respiration}

Mitochondrial respiration was measured using a Clarke type electrode (Eschweiler, Kiel, FRG) in an assay containing $0.5-0.9 \mathrm{ml}$ of a mitochon- drial suspension mixed with $1-1.3 \mathrm{ml}$ respiration buffer at $14.5 \pm 0.3^{\circ} \mathrm{C}$ in a closed glass chamber. The substrates malate and glutamate were added at variable concentrations. $\mathrm{PO}_{2}$ levels in the respiration buffer were adjusted by tonometry (model 237, Instrumentation Laboratory, Milan, Italy) using mixtures of pure $\mathrm{N}_{2}, \mathrm{O}_{2}$ and $\mathrm{CO}_{2}$ prepared by a Multi-Gas-Controller (MKS, Munich, FRG). After stable readings of state 2 respiration, state 3 respiration was elicited by the addition of ADP to a level of 0.2 or $0.6 \mathrm{mmol} \mathrm{l}^{-1}$. Owing to oxyconformity (rates are given for the mean value of a $\mathrm{Po}_{2}$ range $\pm 0.5 \mathrm{kPa}$ ) a clear transition to state 4 respiration could not be identified. Therefore, respiratory control coefficients were calculated by dividing state 3 respiration (respiration with glutamate, malate and ADP) by state 2 respiration (respiration with glutamate and malate without ADP) according to Völkel (1992) and Riefke (1994). The effect of KCN and salicylhydroxamic acid on mitochondrial respiration was studied at levels of $10 \mu \mathrm{mol} \mathrm{l}^{-1}$ or $3 \mathrm{mmol} \mathrm{l}^{-1}$, respectively.

\subsubsection{ATP-synthesis}

ATP-synthesis was determined using a luciferin-luciferase assay (Bio Orbit 1243-102 ATP Monitoring Kit, Turku, Finland) and a Luminescence Spectrometer (Perkin Elmer LS 50B, Hannover, FRG) following the rationale of Wibom et al. (1990). Maximal inhibition of adenylate kinase (EC 2.7.4.3) was achieved by the addition of 50 $\mu \mathrm{mol} \mathrm{P} \mathrm{P}^{1}, \mathrm{P}^{5}$-Di-(adenosin-5')-pentaphosphate $1^{-1}$. ATP production and $\mathrm{O}_{2}$ consumption were measured in the same mitochondrial assay. ATP production was recorded during state 3 respiration for $0.6-1.5 \mathrm{~h}$ in $2-3$ samples, removed from respiration chambers. If necessary, mitochondrial samples were diluted in respiration buffer. $\mathrm{P} / \mathrm{O}$ ratios were calculated as the molar quantity of ATP produced per mol of atomic oxygen consumed $(\mathrm{O})$. The acute influence of external $\mathrm{H}_{2} \mathrm{O}_{2}$ on mitochondrial ATP synthesis was monitored after the addition of $\mathrm{H}_{2} \mathrm{O}_{2}$ directly to the online measurement of ATP production in the luciferin-luciferase system.

\subsubsection{Mitochondrial $\mathrm{H}_{2} \mathrm{O}_{2}$ production}

Mitochondrial $\mathrm{H}_{2} \mathrm{O}_{2}$ production in state 2 and state 3 respiration was analysed by two methods, firstly by fluorimetric analysis, using scopoletin (7-hydroxy-6-methoxy-2H-benzopyran) as a fluo- 
rescence indicator dye in a peroxidase catalyzed reaction in potassium phosphate buffer $(100 \mathrm{mmol}$ $1^{-1}, \mathrm{pH} 7$ ) according to Pamatmat (1990). A luminescence spectrometer (Perkin Elmer, Hannover, FRG) was used at a wavelength of $365 \mathrm{~nm}$ for excitation and $490 \mathrm{~nm}$ for emission recordings. The second method determined oxygen consumption with and without the addition of catalase. Mitochondrial oxygen consumption was monitored and 10-20 $\mu \mathrm{l}$ of a catalase solution were added. $\mathrm{H}_{2} \mathrm{O}_{2}$ production was evaluated from the reduction in oxygen depletion due to $\mathrm{O}_{2}$ production by catalase.

Mitochondrial oxygen uptake linked to transmembrane $\mathrm{H}^{+}$leakage or ROS formation was quantified after the addition of ADP and then, oligomycin $\left(20 \mu \mathrm{mol} \mathrm{l}^{-1}\right)$, thereby eliciting firstly phosphorylation and then maximal inhibition of ATP synthesis. Finally, CCCP was added $(15 \mu \mathrm{mol}$ $\mathrm{CCCP} 1^{-1}$ ) to investigate the $\mathrm{Po}_{2}$ dependence of uncoupled respiration.

In initial experiments centrifugation periods and buffer composition were optimized for the preparation of a nominally catalase free mitochondrial suspension. Determinations of catalase activity in mitochondrial preparations according to Aebi (1985) confirmed that catalase (EC 1.11.1.6) activity remained below detection limits. Studies in another marine worm (Arenicola marina) had demonstrated, that in marine invertebrates catalase is mainly located in the peroxisomal compartment, as it is known for mammals (Buchner et al., 1996).

\subsubsection{Calculation and statistics}

Data are given as individual values or means \pm standard deviations (S.D.). Differences between means were evaluated by Student's $t$-test at a significance level of $5 \%$. The significance of regressions was evaluated by analysis of variance and $F$-test (Stat View II, Abacus Concepts Inc., Berkley CA, USA).

\section{Results}

\subsection{Oxyconformity and energetics}

Mitochondrial respiration was measured at different substrate concentrations. In a first approach malate and glutamate levels were both set to $5 \mathrm{mmol}^{-1}$ and ADP to $0.6 \mathrm{mmol}^{-1}$ following
Riefke (1994). In contrast to the pattern of $\mathrm{Po}_{2}$ independent respiration we saw with bovine heart mitochondria (Tschischka et al., 2000), S. nudus mitochondria displayed a linear and significant increase in oxygen consumption as a function of rising $\mathrm{Po}_{2}(2.8-31.3 \mathrm{kPa})$ from a mean of 56.5-223.9 nmol O mg protein ${ }^{-1} \mathrm{~h}^{-1}$ (Fig. 1). For comparison, 'physiological' substrate concentrations $\left(0.1 \mathrm{mmol}\right.$ malate and glutamate $1^{-1}$ and 0.2 mmol ADP $1^{-1}$ ) did not change the maximum respiration rate or its dependence on $P_{\mathrm{O}_{2}}(n=3$, data not shown). 'Physiological' substrate concentrations were used according to the levels of malate and free ADP in the whole body wall tissue as determined by Pörtner et al. (1984) and Zielinski and Pörtner (1996).

Respiration rates without ADP (state 2, substrates included) seemed equally $P_{\mathrm{O}_{2}}$ dependent as respiration with ADP (state 3), the exact determination being compromised by low respiration rates in state 2 . In consequence and independent of the substrate concentrations applied rising $\mathrm{PO}_{2}$ did not lead to any changes in RCR which remained at a mean level of $3.74 \pm 1.08$.

Mitochondrial ATP synthesis rose significantly in a $\mathrm{Po}_{2}$ range between 10.1 and $31.3 \mathrm{kPa}$ from a mean of 187-279 nmol ATP mg protein ${ }^{-1} \mathrm{~h}^{-1}$ (Fig. 2). Nonetheless, the $\mathrm{P} / \mathrm{O}$ ratio decreased significantly from a mean of 2.08-1.07 at elevated $\mathrm{PO}_{2}$ between 10.1 and $31.3 \mathrm{kPa}$ (Fig. 3). Similar to findings by Riefke (1994) maximal inhibition of mitochondrial respiration at normoxic $\mathrm{Po}_{2}$ occurred by $83 \%$ with $\mathrm{KCN}$ and by up to $60 \%$ with SHAM.

\subsection{Oxyconformity and mitochondrial integrity}

Oxidative injuries of mitochondria could provide a possible explanation for decreasing $\mathrm{P} / \mathrm{O}$ ratios at rising $\mathrm{Po}_{2}$. The effect of external $\mathrm{H}_{2} \mathrm{O}_{2}$ was checked by the addition of $0-90.9 \mu \mathrm{mol}$ $\mathrm{H}_{2} \mathrm{O}_{2} 1^{-1}$ to well coupled mitochondria. The maximal level of $90.9 \mu \mathrm{mol} \mathrm{H}_{2} \mathrm{O}_{2} \mathrm{l}^{-1}$ is 4.6 -fold higher than the $\mathrm{H}_{2} \mathrm{O}_{2}$ concentration formed in coelomic fluid of $S$. nudus under normoxic conditions (T. Buchner, D. Abele, H.O. Pörtner, unpublished). Addition of up to $90.9 \mu \mathrm{mol} \mathrm{H}_{2} \mathrm{O}_{2}$ $1^{-1}$ to the mitochondrial assay even led to a small non-significant increase of ATP synthesis (119.5 $\pm 30 \%, n=3$ ) compared with the level of ATP production without the addition of $\mathrm{H}_{2} \mathrm{O}_{2}$.

In a second experiment respiration rates and 


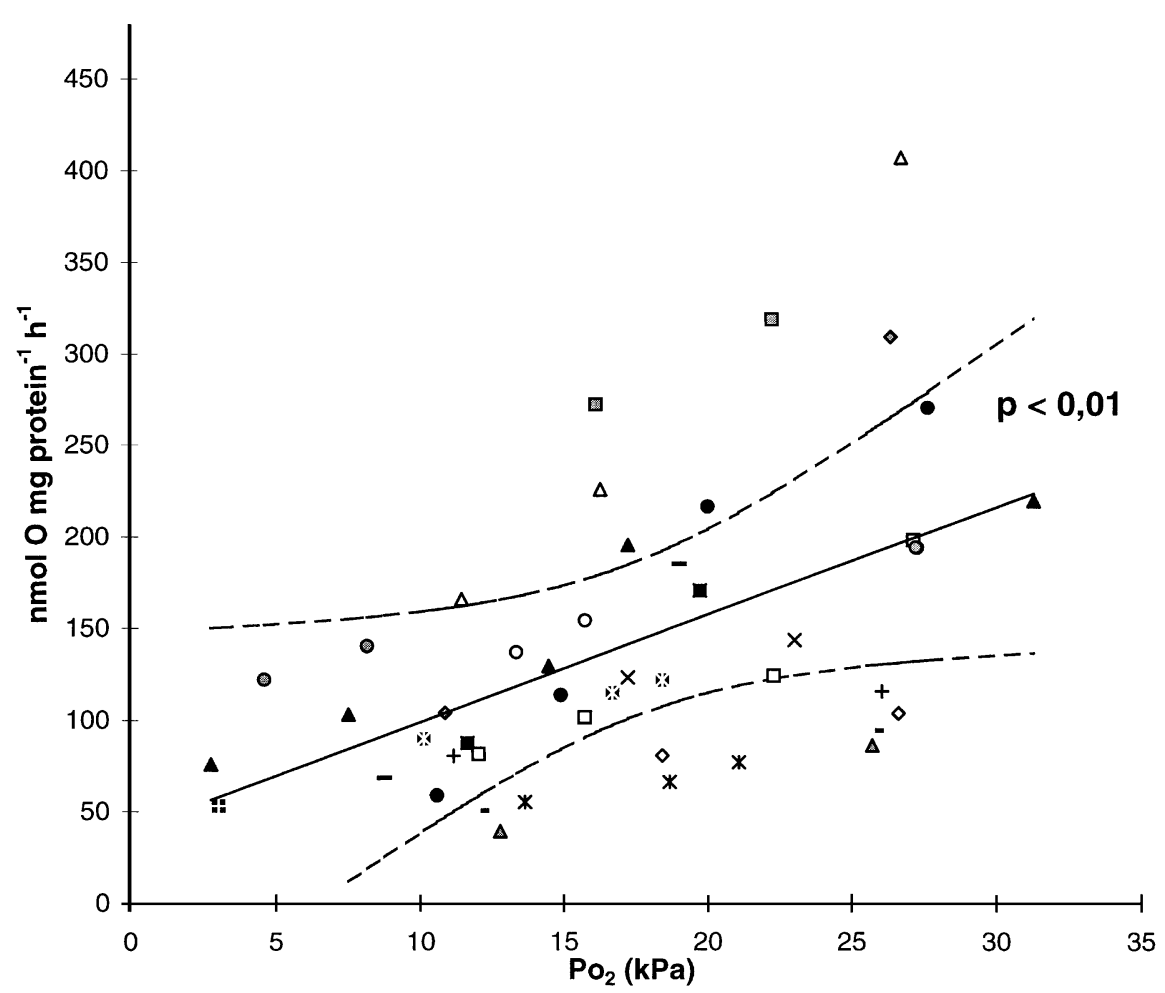

Fig. 1. State 3 respiration in well coupled isolated mitochondria from $S$. nudus body wall muscle as a function of ambient $P \mathrm{o}_{2}$ after the addition of $5 \mathrm{mmol}$ glutamate $\mathrm{1}^{-1}, 5 \mathrm{mmol}$ malate $\mathrm{l}^{-1}$ and $0.6 \mathrm{mmol}$ ADP $\mathrm{l}^{-1}$. One symbol is used for each mitochondrial preparation (same symbols as in Figs. 2 and 3) measured at different $P_{\mathrm{O}_{2}}$ levels, $n=16 .{ }^{*} P<0.01$ indicates the significance level of linear regression.

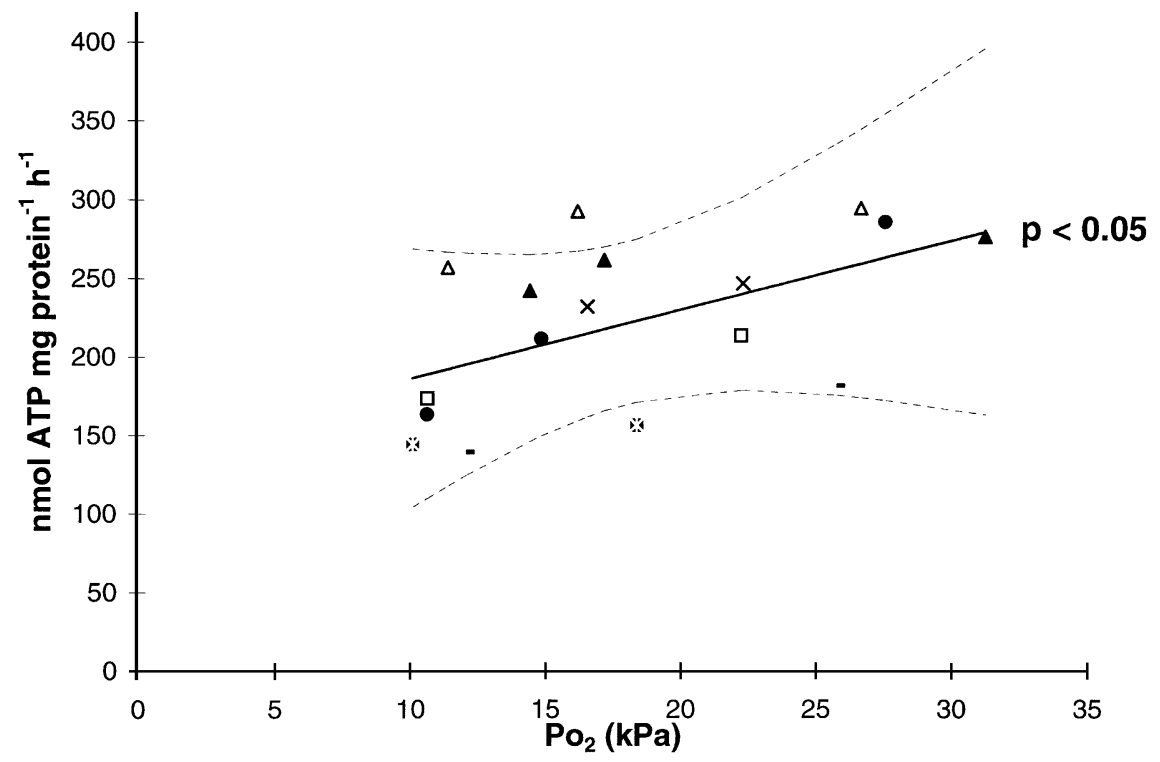

Fig. 2. ATP synthesis at different $P_{\mathrm{O}_{2}}$ levels in well coupled mitochondria of $S$. nudus after the addition of 5 mmol glutamate $1^{-1}, 5$ mmol malate $1^{-1}$ and $0.6 \mathrm{mmol} \mathrm{ADP} 1^{-1}$. One symbol is used for each mitochondrial preparation (same symbols as in Figs. 1 and 3 ) measured at different $P_{\mathrm{O}_{2}}$ levels, $n=7$. ${ }^{*} P<0.05$ indicates the significance level of linear regression. 


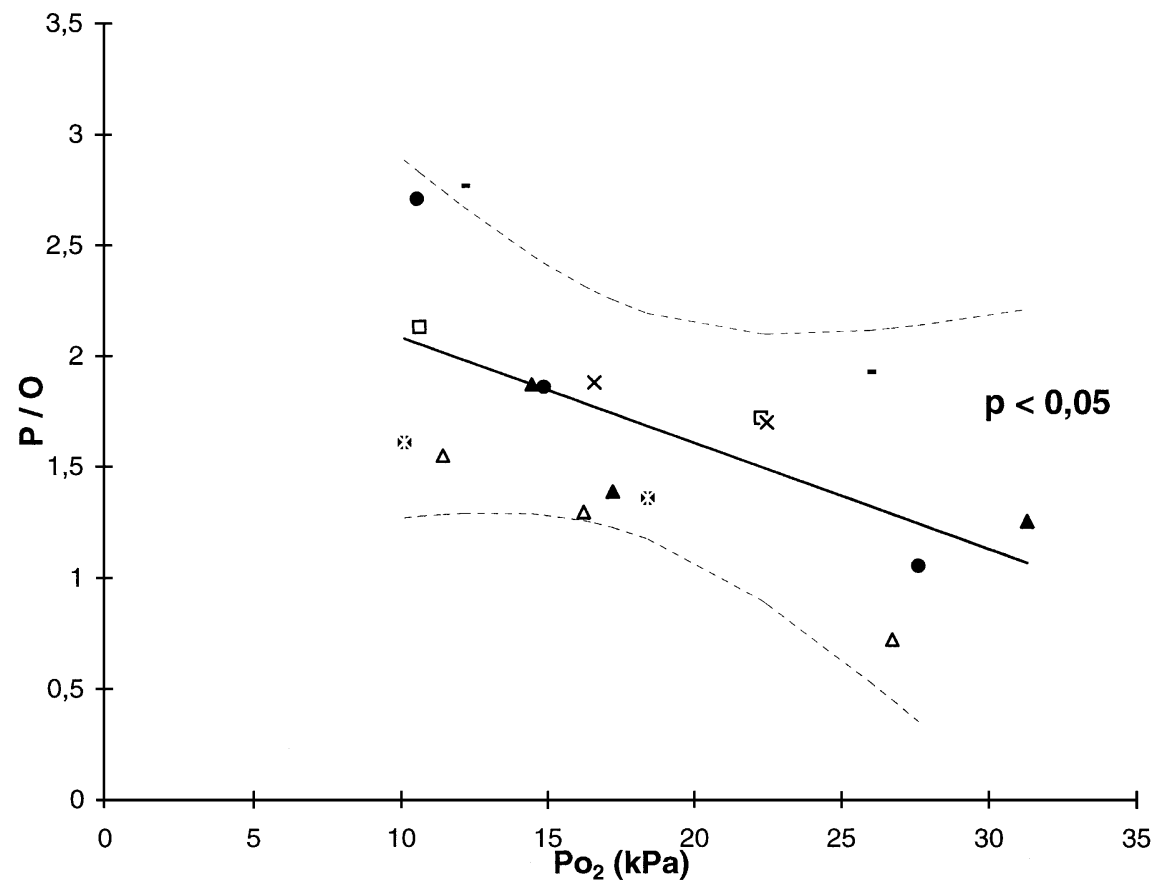

Fig. 3. Mitochondrial $\mathrm{P} / \mathrm{O}$ ratios as a function of ambient $P_{\mathrm{O}_{2}} . \mathrm{P} / \mathrm{O}$ ratios were calculated from dividing ATP production by consumed oxygen $(\mathrm{O})$. One symbol is used for each mitochondrial preparation (same symbols as in Figs. 1 and 2) measured at different $P_{\mathrm{O}_{2}}$ levels, $n=7$. ${ }^{*} P<0.05$ indicates the significance level of linear regression.

ATP synthesis were studied first at high $\mathrm{O}_{2}$ tensions $(26.26 \pm 0.79 \mathrm{kPa})$ and then repeated at lower $\mathrm{O}_{2}$ levels $(16.16 \pm 1.97 \mathrm{kPa}$, still above in vivo intracellular $\mathrm{Po}_{2}$ values of approx. $9 \mathrm{kPa}$ expected under normoxia, Pörtner and Grieshaber, 1993).

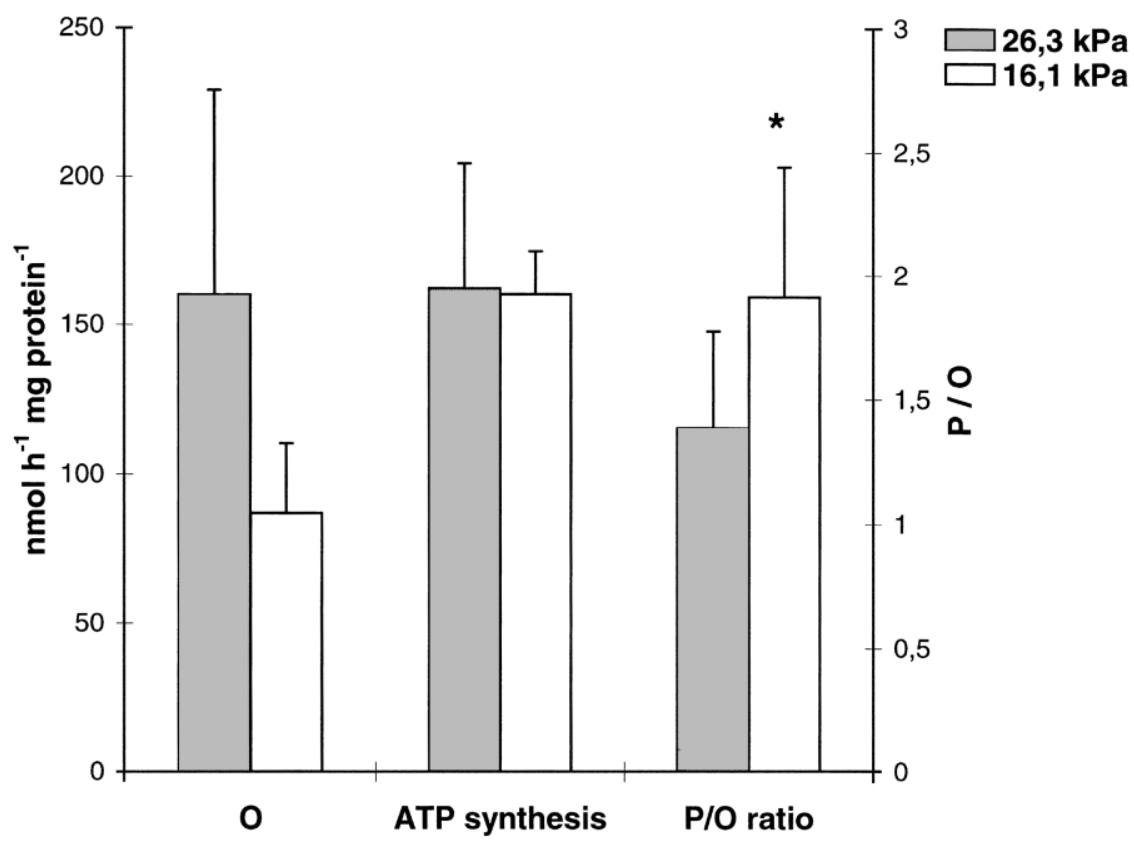

Fig. 4. Reversibility of mitochondrial respiration, ATP production and $\mathrm{P} / \mathrm{O}$ ratio first determined at high $P_{\mathrm{O}_{2}}$ followed by analysis at lower $P_{\mathrm{O}_{2}}$ in the same mitochondria. Values are given as means \pm S.D., $n=4$. ${ }^{*} P<0.05$, significant difference between the two $P \mathrm{O}_{2}$ values, paired sample $t$-test. For more details see text. 
These mitochondria consumed $160.04 \pm 69.02$ nmol O mg protein ${ }^{-1} \mathrm{~h}^{-1}$ and produced $162.32 \pm$ $42.12 \mathrm{nmol}$ ATP mg protein ${ }^{-1} \mathrm{~h}^{-1}$ at high $\mathrm{Po}_{2}$. When $\mathrm{O}_{2}$ levels were reduced, the same mitochondria respired $86.98 \pm 23.36 \mathrm{nmol} \mathrm{O} \mathrm{mg}$ protein $^{-1} \mathrm{~h}^{-1}$ and synthesized ATP at $160.31 \pm 14.53$ nmol ATP mg protein ${ }^{-1} \mathrm{~h}^{-1}$. These data resulted in a low $\mathrm{P} / \mathrm{O}$ ratio of $1.14 \pm 0.39$ at high and a significantly higher ratio of $1.98 \pm 0.53$ at low $\mathrm{Po}_{2}$ (Fig. 4). Moreover, the $\mathrm{P} / \mathrm{O}$ ratio observed at $16,16 \pm 0,39 \mathrm{kPa}$ was the same as in experiments without prior hyperoxic treatment (Fig. 3). These data demonstrate that high respiration rates and decreased $\mathrm{P} / \mathrm{O}$ ratios at high oxygen tensions are completely reversible.

\subsection{Mitochondrial proton leakiness and ROS formation}

Mitochondrial ROS formation consumes $\mathrm{O}_{2}$ consumption without contributing to ATP synthesis. In the inner membrane of vertebrate mitochondria oxygen is reduced at complex I and the ubiquinone-pool (Turrens et al., 1982a,b). Another $\mathrm{O}_{2}$ consuming process is associated with mitochondrial proton conductance. Here protons undergo back diffusion without contributing to phosphorylation. Oligomycin inhibits the ATP synthase. Thus, residual oxygen uptake under oligomycin is a consequence of proton leakiness at high mitochondrial membrane potentials (Brand et al., 1994) and also includes ROS formation. If one or both mechanisms were primarily responsible for the $\mathrm{Po}_{2}$ dependence of respiration and $\mathrm{P} / \mathrm{O}$ ratios, inhibition by oligomycin should be minor and respiration under oligomycin should show the same degree of oxyconformity as oxygen consumption without oligomycin.

In the range between 8.7 and $26.4 \mathrm{kPa}$, there was a small, non-significant increase in oligomycin insensitive oxygen uptake with rising $\mathrm{PO}_{2}$ (Fig. 5). However, the $\mathrm{Po}_{2}$ dependent increase in oxygen consumption of the same mitochondrial sample without oligomycin was 6.7-fold and, therefore, significantly higher (Fig. 5). Moreover, oligomycin insensitive respiration occurred at a rate which contributed a maximum of $6 \%$ to state 3 respiration. Addition of the uncoupler CCCP after the addition of oligomycin, re-established the $\mathrm{PO}_{2}$ dependent increase in oxygen consumption.

These results lead to the conclusion that both mitochondrial proton leakiness and ROS production can only account for maximally $13 \%$ of the observed oxyconformity such that the major part of the phenomenon has to be explained by other mechanisms. In support of these conclusions, mitochondrial $\mathrm{H}_{2} \mathrm{O}_{2}$ formation at several levels of $\mathrm{PO}_{2}(5.06-39.45 \mathrm{kPa})$ occurred below the de-

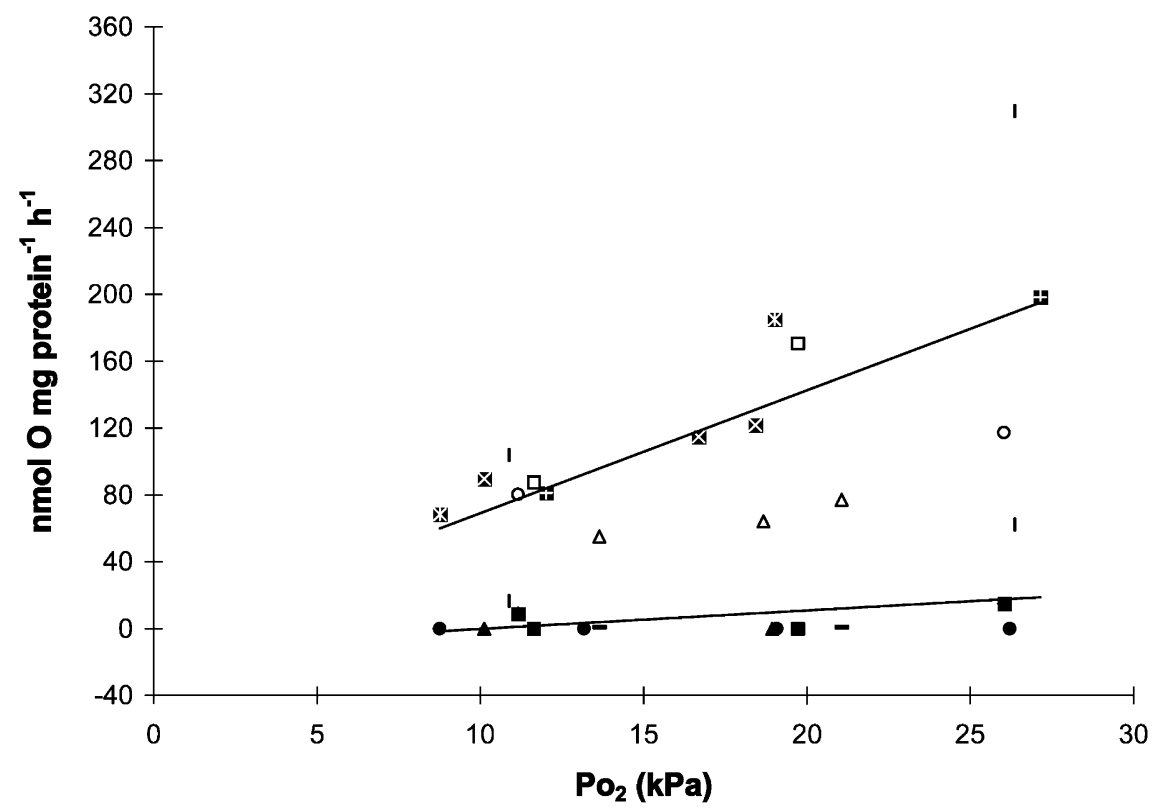

Fig. 5. Mitochondrial state 3 respiration with (filled symbols) and without (open symbols) $20 \mu$ mol oligomycin $1^{-1}$. Each symbol represents one mitochondrial preparation measured at different levels of $P_{\mathrm{o}_{2}}, n=7$. Slopes are significantly different $(P<0.05)$. 
tection limits of the two methods used and confirmed that ROS formation is small and does not significantly contribute to oxygen consumption in $S$. nudus mitochondria.

\section{Discussion}

\subsection{Mitochondrial respiration as the reason for oxyconformity?}

Mean mitochondrial oxygen consumption per $\mathrm{mg}$ mitochondrial protein of $S$. nudus under normoxia is approximately 80-fold lower compared with rat and pigeon mitochondria (Barja et al., 1994), and approximately $40 \%$ lower than mitochondrial oxygen uptake of the lugworm Arenicola marina, another intertidal invertebrate (Völkel and Grieshaber, 1996). The low mitochondrial respiration rate in $S$. nudus relates to the low respiration rate of the whole animal (Pörtner and Grieshaber, 1993).

Mitochondria isolated from the body wall tissue of $S$. nudus displayed strictly oxyconform respiration between 2.8 and $31.3 \mathrm{kPa}$ (Fig. 1). This range covers and extends beyond the values of intracellular $P_{\mathrm{O}_{2}}$ in vivo calculated by Pörtner and Grieshaber (1993) for the range between hypoxia and hyperoxia. The $\mathrm{PO}_{2}$ induced increase of oxygen uptake is the same for the whole animal, for isolated body wall tissue (Pörtner et al., 1985; Riefke, 1994) as well as for isolated muscle cells and coelomic cells (Pörtner and Grieshaber, 1993; Riefke, 1994). Mean respiration rate of the whole animal nearly doubles at a $\mathrm{Po}_{2}$ increment of $13.15 \mathrm{kPa}$, similar to the increase in mitochondrial respiration seen in this study. All of these findings suggest that a mitochondrial mechanism causes oxyconformity in $S$. nudus. This conclusion is also supported by the finding of decreased NADH levels at high $P_{\mathrm{O}_{2}}$ in isolated body wall muscle fibres of $S$. nudus (Riefke, 1994). Such a drop can be explained by the $P_{\mathrm{O}_{2}}$ driven rise in oxygen turnover and, thus, $\mathrm{NADH}$ demand of mitochondria.

Mitochondrial oxyconformity was also found in nereid and bivalve mitochondria (Tschischka et al., 2000). In contrast, cells and mitochondria of oxregulators respire at a constant rate above a critical $\mathrm{Po}_{2}$ (Jöbsis, 1974; Jones and Kennedy, 1982; Jones et al., 1985; Hummerich et al., 1988; Wilson et al., 1988; Rumsey et al., 1990; Pörtner and Grieshaber, 1993; Tschischka et al., 2000). This observation can easily be explained by the high oxygen affinity of cyt $a / a_{3}$, which is saturated above a critical $P_{\mathrm{O}_{2}}$ of $0.1 \mathrm{kPa}$ (Oshino et al., 1974; Jones and Kennedy, 1982).

The $\mathrm{Po}_{2}$ dependence of mitochondrial respiration might be influenced by the levels of mitochondrial substrates. However, our data demonstrate that the pattern of oxyconforming respiration remains unchanged at 'physiological' as well as at saturating substrate concentrations.

\subsection{Energetic consequences of oxyconformity}

Oxyconformity strictly coupled to ATP production would imply a drastic increase in energy turnover at high $P_{\mathrm{O}_{2}}$. Maintenance of ATP turnover despite oxyconforming respiration requires partial or complete uncoupling of ATP production from mitochondrial oxygen uptake. In the case of $S$. nudus the mitochondrial $\mathrm{P} / \mathrm{O}$ ratio declined linearly with rising $P_{\mathrm{O}_{2}}$ (Fig. 3), i.e. the $\mathrm{PO}_{2}$ dependent rise in ATP synthesis occurred at a much slower rate than the increase in oxygen consumption. In contrast, rat brain mitochondria operate at constant ADP/O ratios between 3.95 $\mathrm{kPa}$ and approximately $20 \mathrm{kPa}$ (Khazanov et al., 1992). In a companion study (Tschischka et al., 2000), we also found constant $\mathrm{ADP} / \mathrm{O}$ ratios in bovine heart mitochondria despite high $\mathrm{Po}_{2}(30$ $\mathrm{kPa}$ ), whereas oxyconforming nereid and bivalve mitochondria displayed a drop in $\mathrm{P} / \mathrm{O}$ ratios.

In the present study the calculation of mitochondrial $\mathrm{P} / \mathrm{O}$ ratio used ATP quantities analysed by luminometry in the respiratory assay. In contrast, the 'classical' calculation of $\mathrm{P} / \mathrm{O}$ values uses the amount of ADP added and the total amount of oxygen consumed during state 3 respiration. ADP is assumed to be completely phosphorylated to ATP when state 4 respiration starts (Chance and Williams, 1956). Some authors emphasized problems with this 'classical' approach of determining $\mathrm{P} / \mathrm{O}$ ratios. Especially Hinkle and $\mathrm{Yu}$ (1979) found that up to $10 \%$ of the added ADP had not been converted to ATP at the point of transition of state 3 to state 4 respiration.

The highest mean $\mathrm{P} / \mathrm{O}$ ratio found at a $\mathrm{Po}_{2}$ of $10.1 \mathrm{kPa}$ was 2.08 and a low value of 1.07 was found at $31.3 \mathrm{kPa}$. Assuming a linear increase of the $\mathrm{P} / \mathrm{O}$ ratio with declining $\mathrm{Po}_{2}$, the expected $\mathrm{P} / \mathrm{O}$ ratio at $0.26 \mathrm{kPa}$ would be 2.55 . This is close to a $\mathrm{P} / \mathrm{O}$ ratio of 2.3 expected for NADH oxida- 
tion in the classical electron transport chain (Hinkle, 1995). These considerations support the hypothesis that an alternative oxidase of low oxygen affinity (see below) may contribute to mitochondrial respiration at high $\mathrm{Po}_{2}$ (Pörtner and Grieshaber, 1993).

\subsection{Mitochondrial dysfunction at high $\mathrm{Po}_{2}$ ?}

As an alternative explanation high $\mathrm{Po}_{2}$ might lead to ROS formation, oxidative damage of mitochondrial membranes and in consequence uncoupling of oxygen uptake from ATP synthesis. In rat mitochondria, addition of ROS led to decreased $\mathrm{P} / \mathrm{O}$ ratios, probably due to peroxidation of mitochondrial membrane lipids (Nohl et al., 1978). Elevated $\mathrm{H}_{2} \mathrm{O}_{2}$ concentration in the coelomic plasma of $S$. nudus under hyperoxic conditions (40.77 $\mathrm{kPa}: 29.02 \pm 3.21 \mu \mathrm{mol} \mathrm{H}_{2} \mathrm{O}_{2} \mathrm{l}^{-1}$ ) compared with normoxia $(20.25 \mathrm{kPa}: 19.92 \pm 2.19$ $\mu$ mol $\mathrm{H}_{2} \mathrm{O}_{2} 1^{-1}$, T. Buchner, D. Abele and H.O. Pörtner, unpublished) indicate $\mathrm{Po}_{2}$ dependent ROS formation in this species in vivo. However, an inhibitory effect on ATP synthesis was not found, when mitochondria were exposed to $\mathrm{H}_{2} \mathrm{O}_{2}$ concentrations chosen equivalent to coelomic levels under normoxia or even threefold higher.

Irreversible damage by $\mathrm{Po}_{2}$ induced production of reactive oxygen species has been described for vertebrate mitochondria (Boveris and Chance, 1973; Loschen et al., 1973; Turrens et al., 1982a, Barja et al., 1994). Pathophysiological peroxidative mitochondrial membrane damage by hyperoxic exposure has been described by Nohl et al. (1981) for heart cells of rats. In S. nudus oxyconformity and $\mathrm{PO}_{2}$ dependent $\mathrm{P} / \mathrm{O}$ ratios were found to be completely reversible (Fig. 4), thereby excluding mitochondrial damage by ROS formation during the time course of the experiments.

\subsection{Mitochondrial mechanisms behind oxyconformity}

$\mathrm{PO}_{2}$ dependent proton leakiness or ROS formation would also explain declining $\mathrm{P} / \mathrm{O}$ ratios at higher $\mathrm{Po}_{2} \cdot \mathrm{Po}_{2}$ dependent ROS formation has been described for pigeon heart and porcine lung mitochondria (Turrens et al., 1982a,b). However, the high degree of inhibition by oligomycin in $S$. nudus mitochondria suggests that mitochondrial respiration includes only a small fraction of proton leakage or ROS formation. Therefore, any contribution of proton leakiness or ROS production to oxyconformity in $S$. nudus would be minor.

Groups of bacteria, e.g. species of Acetobacter, Azotobacter, Paracoccus and Escherichia coli possess a branched respiratory system, also postulated to exist in mitochondria of endoparasitic nematodes and helminths (Cheah, 1967; Paget et al., 1988). One of the final oxidases is cytochrome $o$ (Smith, 1961; Matsushita et al., 1984; Moat and Foster, 1988). Cytochrome $o$ (also termed as cytochrome $b o$ ) is a $b$-type cytochrome (White, 1995). Some bacteria, like the facultative anaerobe Staphylococcus albus, use only cytochrome $o$ as the final oxidase (Smith, 1961). In E. coli this cytochrome displays a low oxygen affinity (Schlegel, 1992) and leads to oxyconforming respiration of the cell (Daniel, 1970) comparable with oxyconformity of $S$. nudus mitochondria. Electron flux through the cytochrome $o$ pathway is characterized by a reduced number of phosphorylation sites, compared to the classical respiration chain terminated by cyt $a / a_{3}$ (Sone, 1990; White, 1995). In our view the presence of a similar branched respiratory chain is a possible explanation for oxyconformity in $S$. nudus mitochondria and their progressive uncoupling at high $\mathrm{Po}_{2}$.

A cytochrome $O$ controlled pathway is also discussed for other infaunal marine invertebrates (Pörtner and Grieshaber, 1993; Tschischka et al., 2000). Moreover, an alternative oxidase is suggested to be involved in $\mathrm{H}_{2} \mathrm{~S}$ oxidation in marine invertebrates (Völkel and Grieshaber, 1996). The predominant evidence for cytochrome $o$ in many studies is the presence of KCN insensitive, SHAM (salicylhydroxamic acid) sensitive mitochondrial respiration. SHAM is used as an inhibitor of the alternative oxidase. This evidence is not unequivocal, however, since some studies indicate, that SHAM not only inhibits the alternative oxidase but also the 'classical' electron transport chain (Siedow and Bickett, 1981). According to these authors SHAM might act as a competitive inhibitor of electron transfer from ubiquinone to the alternative oxidase. In bacteria $\mathrm{KCN}$ inhibits cytochrome $c$ oxidase as well as cytochrome $o$, in contrast to the $\mathrm{KCN}$ resistance of cytochrome $d$, another bacterial final oxidase (Sone, 1990) characterized by reduced phosphorylation efficiency (Jones, 1977). Inhibition by KCN as well as by SHAM was found in oxyconforming mitochondrial preparations of this study and a companion 
paper (Tschischka et al., 2000). These findings support the existence of a branched respiratory system in $S$. nudus and other marine oxyconformers.

The endproduct of oxygen reduction by cytochrome $o$ is not quite clear. Some studies suggested that mitochondria produce $\mathrm{H}_{2} \mathrm{O}_{2}$ during respiration via cyt $O$ in nematodes and helminths (Cheah, 1967; Paget et al., 1988). However, increasing $\mathrm{H}_{2} \mathrm{O}_{2}$ production due to elevated $\mathrm{Po}_{2}$ also occurs in oxyregulating vertebrate mitochondria (Turrens et al., 1982a). In the nematode Nippostrongylus brasiliensis Paget et al. (1987) found that $\mathrm{H}_{2} \mathrm{O}_{2}$ formation does not involve cytochrome $o$, but rather a side reaction of the classical mammalian-like electron transport pathway. Determination of the $\mathrm{NADH} / \mathrm{O}_{2}$ ratio in groups of $E$. coli with and without cytochrome $o$ led to the conclusion, that this bacterial cytochrome $o$ does not produce $\mathrm{H}_{2} \mathrm{O}_{2}$, but $\mathrm{H}_{2} \mathrm{O}$ as in the 'classical' electron transport chain (Elstner, 1990). Matsushita et al. (1984) and Sone (1990) also described $\mathrm{H}_{2} \mathrm{O}$ to be the only end product of bacterial cyt $o$. In our study $\mathrm{H}_{2} \mathrm{O}_{2}$ formation was not detectable in the $\mathrm{Po}_{2}$ range between 5.26 and $39.45 \mathrm{kPa}$ in well coupled mitochondria of $S$. nudus, suggesting that $\mathrm{H}_{2} \mathrm{O}_{2}$ is not produced in high enough quantities to be the final end product of the cytochrome $o$ reaction in $S$. nudus. Accordingly, the alternative oxidase of this oxyconformer should produce $\mathrm{H}_{2} \mathrm{O}$ rather than $\mathrm{H}_{2} \mathrm{O}_{2}$.

\subsection{Ecophysiological implications}

Pörtner and Grieshaber (1993) hypothesized that an alternative electron transport chain might not only be present in parasitic helminths (Bryant et al., 1989) but also in invertebrates from hypoxic environments as an ancient mechanism of protection from toxic oxygen. High rates of oxygen consumption might be used to reduce excessive ambient oxygen (respiratory protection) in closed environments like the animals' burrow. Model calculations by Pörtner and Grieshaber (1993) indicate that, owing to elevated oxygen consumption, the $\mathrm{PO}_{2}$ gradient between coelomic fluid and mitochondria increases at high ambient $\mathrm{PO}_{2}$ such that the rise in intracellular $\mathrm{Po}_{2}$ induced by hyperoxic exposure is less than at constant metabolic rates. Nonetheless, these calculations still reveal an increase in intracellular $\mathrm{Po}_{2}$ during hyperoxia. This increase is responsible for the pattern of oxyconforming respiration observed in vivo.

In vertebrates reoxygenation after ischaemic conditions leads to increased ROS production (Elstner, 1990). Presumably, oxyconformity protects $S$. nudus from such oxidative stress (respiratory protection). In fact the levels of antioxidant enzymes in $S$. nudus are low, compared to vertebrates, but also to other marine invertebrates $(\mathrm{T}$. Buchner, D. Abele and H.O. Pörtner, unpublished). This finding is presumably related to the low respiration rate of the animal, but protection against ROS formation in mitochondria by an alternative, branched electron pathway could also be one reason. For plant mitochondria Popov et al. (1997) observed that $\mathrm{H}_{2} \mathrm{O}_{2}$ production is strongly stimulated by inhibition of the alternative oxidase and concluded that an alternative oxidase contributes to antioxidant defence. A protective effect against oxygen toxicity was shown for the branched respiratory system in the bacterium Azotobacter vinelandii, which possesses an extremely oxygen sensitive nitrogenase. In this case cytochrome $d$ is used to deplete oxygen in the vicinity of the enzyme (Jones, 1977; Gottschalk, 1986; D’Mello et al., 1994; Bertsova et al., 1997). All of these considerations corroborate the conclusion that the alternative electron pathway contributes to oxygen detoxification under the variable $\mathrm{O}_{2}$ conditions of the habitat of oxyconforming animals.

\section{References}

Abele, D., Großpietsch, H., Pörtner, H.O., 1998. Temporal fluctations and spatial gradients of environmental $\mathrm{Po}_{2}$, temperature, $\mathrm{H}_{2} \mathrm{O}_{2}$ and $\mathrm{H}_{2} \mathrm{~S}$ in intertidal habitat trigger enzymatic antioxidant protection in the capitellide worm Heteromastus filiformis. Mar. Ecol. Prog. Ser. 163, 179-191.

Aebi, H.E., 1985. Catalase. In: Bergmeyer, H.U. (Ed.), . Methods of Enzymatic Analysis, VIII. Verlag Chemie, Weinheim, pp. 273-286.

Barja, G., Cadenas, S., Rojas, C., Pérez-Campo, R., Lòpez-Torres, M., 1994. Low mitochondrial free radical production per unit $\mathrm{O}_{2}$ consumption can explain the simultaneous presence of high longevity and high aerobic metabolic rate in birds. Free Rad. Res. 21, 317-328.

Bertsova, Y.V., Bogachev, A.V., Skulachev, V.P., 1997. Generation of protonic potential by the $b d$-type quinol oxidase of Azotobacter vinelandii. FEBS Lett. 414, 369-372. 
Boveris, A., Chance, B., 1973. The mitochondrial generation of hydrogen peroxide. Biochem. J. 134, 707-716.

Bradford, M.M., 1976. A rapid and sensitive method for the quantitation of microgram quantities of protein utilizing the principle of protein-dye binding. Anal. Biochem. 72, 248-254.

Brand, M.D., Chien, L.-F., Ainscow, E.K., Rolfe, D.F.S., Porter, R.K., 1994. The causes and functions of mitochondrial proton leak. Biochim. Biophys. Acta 1187, 132-139.

Bryant, C., Behm, C.A., Howell, M.J., 1989. Biochemical Adaptations in Parasites. Chapman and Hall, London.

Buchner, T., Abele-Oeschger, D., Theede, H., 1996. Aspect of antioxidant status in the polychaete Arenicola marina: tissue and subcellular distribution, and reaction to environmental hydrogen peroxide and elevated temperatures. Mar. Ecol. Prog. Ser. 143, 141-150.

Chance, B., Williams, G.R., 1956. The respiratory chain and oxidative phosphorylation. Adv. Enzymol. 17, 65-134.

Cheah, K.S., 1967. The oxidase systems of Monieza expansa (Cestoda). Comp. Biochem. Physiol. 2, 277-302.

Daniel, R.M., 1970. The electron transport system of Acetobacter suboxidans with particular reference to cytochrome $o$. Biochim. Biophys. Acta 216, 328-341.

Dejours, P., 1981. Principles of Comparative Physiology. North-Holland, Amsterdam.

D’Mello, R., Hill, S., Poole, R.K., 1994. Determination of the oxygen affinities of terminal oxidases in $\mathrm{AzO}$ tobacter vinelandii using the deoxygenation of oxyleghaemoglobin and oxymyoglobin: cytochrome $b d$ is a low-affinity oxidase. Microbiology 140, 1395-1402.

Elstner, E.F., 1990. Der Sauerstoff: Biochemie, Biologie, Medizin. BI Wissenschaftsverlag, Mannheim.

Fenchel, T., Finlay, B.J., 1995. Ecology and Evolution in Anoxic Worlds. Oxford University Press, New York, p. 276.

Fritzsche, D., 1995. Leistungsanalytische und resistenzökologische Untersuchungen zur Emanzipation des Polychaeten Marenzelleria viridis (Verrill 1873) gegenüber den Faktoren Salinität und Sauerstoffpartialdruck. Dissertation. Universität Rostock.

Gottschalk, G., 1986. Bacterial Metabolism, second ed Springer, New York.

Henze, M., 1910. ber den Einfluss des Sauerstoffs auf den Gaswechsel einiger Meerestiere. Biochem. Z. 26, 255-278.

Hinkle, P.C., 1995. Oxygen, proton and phosphate fluxes, and stoichiometries. In: Brown, G.C., Cooper, C.E. (Eds.), Bioenergetics. Oxford University Press, Oxford, pp. 1-16.
Hinkle, P.C., Yu, M.L., 1979. The phosphorus/oxygen ratio of mitochondrial oxidative phosphorylation. J. Biol. Chem. 254, 2450-2455.

Hummerich, H., de Groot, H., Noll, T., Soboll, S., 1988. Dependence of mitochondrial and cytosolic adenine nucleotides on oxygen partial pressure in isolated hepatocytes. Biochem. J. 250, 641-645.

Jöbsis, F.F., 1974. Intracellular metabolism of oxygen. Proceedings of the Conference on the Scientific Basis of Respiratory Therapy, 58-63.

Jones, C.W., 1977. Aerobic respiratory systems in bacteria in microbial energetics. In: Haddock, B.A., Hamilton, W.A. (Eds.), Twenty-seventh Symposium of the Society for General Microbiology, Imperial College London, Cambridge. Cambridge University Press, London.

Jones, D.P., Kennedy, F.G., 1982. Intracellular oxygen supply during hypoxia. Am. J. Physiol. 243, C247-253.

Jones, D.P., Kennedy, F.G., Andersson, B.S., Aw, T.Y., Wilson, E., 1985. When is a mammalian cell hypoxic? Insights from studies of cells versus mitochondria. J. Mol. Physiol. 8, 473-482.

Khazanov, V.A., Poborsky, A.N., Kondrashova, M.N., 1992. Air saturation reduces the rate of phosphorylating oxidation of succinate in isolated mitochondria. FEBS Lett. 314, 264-266.

Kresze, G.-B., 1983. Methods of protein determination. In: Bergmeyer, H.U. (Ed.), . Methods of Enzymatic Analysis, 2. Verlag Chemie, Weinheim.

Loschen, G., Azzi, A., Flohé, L., 1973. Mitochondrial $\mathrm{H}_{2} \mathrm{O}_{2}$ formation: relationship with energy conservation. FEBS Lett. 33, 84-88.

Mangum, C., van Winkle, W., 1973. Response of aquatic invertebrates to declining oxygen tensions. Am. Zool. 13, 529-545.

Matsushita, K., Patel, L., Kaback, R., 1984. Cytochrome $o$ type oxidase from Escherichia coli. Characterization of the enzyme and mechanism of electrochemical protone gradient generetion. Biochemistry 23, 4703-4714.

Moat, A.G., Foster, J.W., 1988. Microbial Physiology, second ed Wiley, New York.

Nohl, H., Breuninger, V., Hegner, D., 1978. Influence of mitochondrial radical formation on energy-linked respiration. Eur. J. Biochem. 90, 385-390.

Nohl, H., Hegner, D., Summer, K.-H., 1981. The mechanism of toxic action of hyperbatric oxygenation on the mitochondria of rat-heart cells. Biochem. Pharmacol. 30, 1753-1757.

Oshino, N., Sugano, T., Oshino, R., Chance, B., 1974. Mitochondrial function under hypoxic conditions: the steady states of cytochrome $a+a_{3}$ and their relation to mitochondrial energy states. Biochim. Biophys. Acta 368, 298-310.

Pamatmat, M.M., 1990. Catalase activity: a variable 
affecting $\mathrm{H}_{2} \mathrm{O}_{2}$ distribution in Kiel Bight. Meeresforschung 32, 261-275.

Paget, T.A, Fry, M., Lloyd, D., 1987. Effects of inhibitors on the oxygen kinetic of Nippodtrongylus brasiliensis. Mol. Biochem. Parasitol. 22, 125-133.

Paget, T.A., Fry, M., Lloyd, D., 1988. The $\mathrm{O}_{2}$-dependence of respiration and $\mathrm{H}_{2} \mathrm{O}_{2}$ production in the parasitic nematode Ascaridia galli. Biochem. J. 256, 633-639.

Popov, V.N., Simonian, R.A., Skulachev, V.P., Starkov, A.A., 1997. Inhibition of the alternative oxidase stimulates $\mathrm{H}_{2} \mathrm{O}_{2}$ production in plant mitochondria. FEBS Lett. 415, 87-90.

Pörtner, H.O., Grieshaber, M.K., 1993. Critical $P_{\mathrm{o}_{2}}$ (s) in oxyconforming and oxyregulatoring animals: gas exchange, metabolic rate and the mode of energy production. In: Bicudo, J.E.P.W. (Ed.), The Vertebrate Gas Transport Cascade: Adaptations to Environment and Mode of Live. CRC Press, Boca Raton, FL, pp. 330-357.

Pörtner, H.O., Kreutzer, U., Siegmund, B., Heisler, N., Grieshaber, M.K., 1984. Metabolic adaptations of the intertidal worm Sipunculus nudus to functional and environmental hypoxia. Marine Biol. 79, 237-247.

Pörtner, H.O., Heisler, N., Grieshaber, M.K., 1985. Oxygen consumption and mode of energy production in the intertidal worm Sipunculus nudus L.: definition and characterization of the critical $P_{\mathrm{O}_{2}}$ for an oxyconformer. Resp. Physiol. 59, 361-377.

Prosser, C.L. (Ed.), 1991. Comparative Animal Physiology. Wiley-Liss, New York.

Rehm, H., 1996. Der Experimentator: Proteinbiochemie. Gustav Fischer Verlag, Stuttgart.

Riefke, B., 1994. Untersuchungen über die zelluläre Regulation des Sauerstoffverbrauchs mariner Oxykonformer. Dissertation. Universität Düsseldorf.

Rumsey, W.L., Schlosser, C., Nuutinen, E.M., Robiolio, M., Wilson, D.F., 1990. Cellular energetics and the oygen dependence of respiration in cardiac myocytes isolated from adult rat. J. Biol. Chem. 265, 15392-15399.

Schlegel, H.G., 1992. Allgemeine Mikrobiologie. Georg Thieme Verlag, Stuttgart.

Siedow, J.N., Bickett, D.M., 1981. Structural features required for inhibition of cyanid-insensitive electron transfer by propyl gallate. Arch. Biochem. Biophys. 207, 32-39.
Smith, L., 1961. The Bacteria, vol. II. Academic Press, New York.

Sone, N., 1990. Respiration-driven proton pumps. In: Krulwich, T.A. (Ed.), Bacterial Energetics. The Bacteria, XII. Academic Press, San Diego, CA.

Sugano, T., Oshino, N., Chance, B., 1974. Mitochondrial function under hypoxic conditions: the steady states of cytochrome $c$ reduction and of energy metabolism. Biochim. Biophys. Acta 347, 340-358.

Tschischka, K., Abele, D., Pörtner, H.O., 2000. Mitochondrial oxyconformity and cold adaptation in the polychaete Nereis pelagica and the bivalve Arctica islandica from the Baltic and White Seas. J. Exp. Biol. 203, 3355-3368.

Turrens, J.F., Freemann, B.A., Capro, J.D., 1982a. Hyperoxia increases $\mathrm{H}_{2} \mathrm{O}_{2}$ release by lung mitochondria and microsomes. Arch. Biochem. Biophys. 217, 411-421.

Turrens, J.F., Freemann, B.A., Levitt, J.G., Crapo, J.D., 1982b. The effect of hyperoxia on superoxide production by lung submitochondrial particles. Arch. Biochem. Biophys. 217, 401-410.

Völkel, S., 1992. Ökophysiologische Untersuchungen über die Sulfidtoleranz des Wattwurmes Arenicola marina L. Dissertation. Universität Düsseldorf.

Völkel, S., Grieshaber, M.K., 1996. Mitochondrial sulfide oxidation in Arenicola marina: evidence for alternative electron pathway. Eur. J. Biochem. 235, 231-237.

White, D., 1995. The Physiology and Biochemistry of Prokaryotes. Oxford University Press, New York.

Wibom, R., Lundin, A., Hultman, E., 1990. A sensitive method for measuring ATP-formation in rat muscle mitochondria. Scand. J. Clin. Lab. Invest. 50, 143-152.

Wilson, D.F., Owen, C.S., Erecinska, M., 1979. Quantitative dependence of mitochondrial oxidative phosphorylation on oxygen concentration: a mathematical model. A. Biochem. Biophys. 195, 494-504.

Wilson, D.F., Rumsey, W.L., Green, T.J., Vanderkooi, J.M., 1988. The oxygen dependence of mitochondrial oxidative phosphorylation measured by a new optical method for measuring oxygen concentration. J. Biol. Chem. 263 (6), 2712-2718.

Zielinski, S., Pörtner, H.O., 1996. Energy metabolism and ATP free-energy change of the intertidal worm Sipunculus nudus below a critical temperature. J. Comp. Physiol. B 166, 492-500. 